\title{
Synaptojanin 1 Contributes to Maintaining the Stability of GABAergic Transmission in Primary Cultures of Cortical Neurons
}

\author{
Anita Lüthi, ${ }^{1}$ Gilbert Di Paolo,, ${ }^{2}$ Ottavio Cremona, ${ }^{3}$ Laurie Daniell,, ${ }^{2}$ Pietro De Camilli, ${ }^{2}$ and \\ David A. McCormick ${ }^{1}$ \\ ${ }^{1}$ Section of Neurobiology, ${ }^{2}$ Department of Cell Biology and Howard Hughes Medical Institute, Yale University, School of \\ Medicine, New Haven, Connecticut 06510, and 'Dipartimento di Scienze Mediche, Università del Piemonte Orientale "A. \\ Avogadro," Novara, Italy
}

Inhibitory synapses in the CNS can exhibit a considerable stability of neurotransmission over prolonged periods of highfrequency stimulation. Previously, we showed that synaptojanin 1 (SJ1), a presynaptic polyphosphoinositide phosphatase, is required for normal synaptic vesicle recycling (Cremona et al., 1999). We asked whether the stability of inhibitory synaptic responses was dependent on SJ1. Whole-cell patch-clamp recordings of unitary IPSCs were obtained in primary cortical cultures between cell pairs containing a presynaptic, fastspiking inhibitory neuron $\left(33.5-35^{\circ} \mathrm{C}\right)$. Prolonged presynaptic stimulation (1000 stimuli, 2-20 Hz) evoked postsynaptic responses that decreased in size with a bi-exponential time course. A fast component developed within a few stimuli and was quantified with paired-pulse protocols. Paired-pulse depression (PPD) appeared to be independent of previous GABA release at intervals of $\geq 100 \mathrm{msec}$. The characteristics of PPD, and synaptic depression induced within the first $\sim 80$ stimuli in the trains, were unaltered in SJ1-deficient inhibitory synapses.
A slow component of depression developed within hundreds of stimuli, and steady-state depression showed a sigmoidal dependence on stimulation frequency, with half-maximal depression at $6.0 \pm 0.5 \mathrm{~Hz}$. Slow depression was increased when release probability was augmented, and there was a small negative correlation between consecutive synaptic amplitudes during steady-state depression, consistent with a presynaptic depletion process. Slow depression was increased in SJ1deficient synapses, with half-maximal depression at $3.3 \pm 0.9$ $\mathrm{Hz}$, and the recovery was retarded $\sim 3.6$-fold. Our studies establish a link between a distinct kinetic component of physiologically monitored synaptic depression and a molecular modification known to affect synaptic vesicle reformation.

Key words: inhibitory synaptic transmission; synaptic depression; short-term plasticity; vesicle recycling; clathrin-mediated endocytosis; synaptojanin; phosphoinositide metabolism
Synapses are temporarily altered in strength when activated repetitively. Activity-dependent adjustments range from transient enhancement to transient depression of synaptic transmission and develop on time scales from milliseconds to seconds and minutes (for review, see Zucker, 1989, 1996). In the CNS, the property of a synapse to undergo facilitation or depression is determined by both the physiological characteristics of the neuron establishing this synapse and the identity of the postsynaptic target (for review, see Thomson and Deuchars, 1997; Gupta et al., 2000; Thomson, 2000; Tóth and McBain, 2000). On average, however, it appears that a considerable population of synapses formed by fast-spiking interneurons in the neocortex show a more moderate depression in comparison with excitatory synapses, in particular during stimulation at higher frequencies (5-20 Hz) (Galarreta and Hestrin, 1998; Varela et al., 1999). The relatively weaker steady-state depression of inhibitory versus excitatory synapses

\footnotetext{
Received July 24, 2001; revised Sept. 5, 2001; accepted Sept. 12, 2001.

This work was supported in part by National Institutes of Health Grants to P.D. (NS36251 and CA46128) and D.A.M. (NS26143), by Telethon (project D.111) and MIUR (COFIN2000) grants to O.C., and a European Molecular Biology Organization long-term fellowship to G.D. We thank the members of the De Camilli and McCormick laboratories for stimulating discussions, and Dr. J. Brumberg for helpf ul comments and critical reading of this manuscript.

Correspondence should be addressed to Dr. A. Lüthi, Department of Pharmacology and Neurobiology, Biozentrum, Klingelbergstrasse 70, CH-4056 Basel, Switzerland. E-mail: anita.luthi@unibas.ch.

Copyright (C) 2001 Society for Neuroscience $\quad 0270-6474 / 01 / 219101-11 \$ 15.00 / 0$
}

may represent a mechanism to stabilize prolonged network discharges in recurrent cortical circuits.

What are the endogenous synaptic factors maintaining neurotransmitter release during repetitive activation? The speed of vesicular recycling may be rate limiting in stabilizing synaptic efficacy (Brodin et al., 1997; Dittman and Regehr, 1998; Wang and Kaczmarek, 1998; Weis et al., 1999; Kraushaar and Jonas, 2000; von Gersdorff, 2001). The first step of vesicle recycling is the retrieval of the recently fused vesicle from the plasma membrane, a process in which clathrin-mediated endocytosis plays a dominant role (for review, see De Camilli et al., 1996, 2000; Augustine et al., 1999). Clathrin-mediated endocytosis requires a cooperation of intrinsic coat components and accessory factors (Brodin et al., 2000; Owen and Luzio, 2000; Slepnev and De Camilli, 2000). One such factor is synaptojanin 1 (SJ1), a presynaptically highly enriched polyphosphoinositide phosphatase (McPherson et al., 1996; Haffner et al., 1997; Cremona and De Camilli, 2001). Disruption of the function of synaptojanin either genetically or by antibody and peptide microinjections causes an accumulation of clathrin-coated vesicles in an actin-rich cytomatrix around the synaptic vesicle cluster, suggesting a retarded reentry of vesicles into synaptic vesicle pools (Cremona et al., 1999; Gad et al., 2000; Harris et al., 2000). The widespread expression of SJ1 at both excitatory and inhibitory nerve terminals in the CNS suggests a general role of this protein in synaptic physiology (McPherson et al., 1996; Kudo et al., 1999). 
Synaptojanin 1 may be particularly critical in central synapses that exhibit maintained responsiveness during prolonged stimulation, because these synapses may be dependent on efficient resupply of vesicles. To address this possibility, synaptic transmission between cultured fast-spiking inhibitory neurons, which show relatively stable responses during repeated activation in acute preparations (Galarreta and Hestrin, 1998; Kraushaar and Jonas, 2000), was investigated. Indeed, the activity of SJ1 was required to maintain the strength of inhibitory synaptic transmission during repetitive stimulation, thus suggesting a critical role of phosphoinositide metabolism in this characteristic stability of inhibitory neurons.

Preliminary results have been reported previously in abstract form (Lüthi et al., 2000).

\section{MATERIALS AND METHODS}

Primary culture. Low-density cortical cultures were prepared from neonatal mouse brains as described previously (Banker and Goslin, 1991; Ryan et al., 1996). Briefly, cortical tissue was rapidly dissected out, placed in ice-cold sterile HBSS, and minced with a scalpel until pieces were $<1$ $\mathrm{mm}^{3}$. Tissue was then digested for 45-60 $\mathrm{min}$ in an activated enzyme solution containing papain $(20 \mathrm{U} / \mathrm{ml})$ and DNase $(20 \mu \mathrm{g} / \mathrm{ml})$ at $37^{\circ} \mathrm{C}$, followed by gentle trituration with fire-polished Pasteur pipettes with decreasing tip diameter. Cell suspensions were plated in glialconditioned medium onto poly-D-lysine-coated coverslips to a density of $12,000-20,000 \mathrm{cells} / \mathrm{cm}^{2}$. The day after plating, the medium was exchanged to Neurobasal/B27 serum-free medium (Life Technologies, Gaithersburg, MD), and cells were maintained at $37^{\circ} \mathrm{C}$ in a $5 \% \mathrm{CO}_{2}$ humidified incubator. Cultures were used for electrophysiological recordings 2.5-4 weeks after plating.

Electrophysiological recordings. Paired whole-cell recordings were obtained from cultured cortical neurons under visual control using differential interference contrast microscopy via an upright Axioscope (Zeiss) at $33.5-35^{\circ} \mathrm{C}$. Patch pipettes were pulled from borosilicate glass tubing (World Precision Instruments; TW150F-4, outer diameter $1.5 \mathrm{~mm}$ ) on a PP-83 Narishige puller and filled with the following solution (in $\mathrm{mM}$ ): 110 KGluconate, $10 \mathrm{KCl}, 10 \mathrm{HEPES}, 1 \mathrm{Na}-\mathrm{EGTA}, 0.55 \mathrm{CaCl}_{2}, 2 \mathrm{MgCl}_{2}, 2$ $\mathrm{Na}_{2} \mathrm{ATP}, 0.2 \mathrm{NaGTP}$, adjusted to $290 \mathrm{mOsm}$ with sucrose, $\mathrm{pH} 7.25$, pCa 7. For the postsynaptic neuron, KGluconate was replaced with CsGluconate, and $1 \mathrm{~mm}$ Lidocaine $N$-ethyl bromide (QX-314) was added. Fresh ATP, GTP, and QX-314 were added daily from stocks (100-fold concentrated). The resistance of the electrodes was 3-5 M $\Omega$ and yielded series resistances in the range between 15 and $30 \mathrm{M} \Omega$ that were compensated in current-clamp mode in the presynaptic cell and not compensated in the postsynaptic cell. Series resistance of the postsynaptic cell was checked for stability regularly during the experiments, and if it changed by $>20 \%$ the experiment was discontinued. In some experiments, the presynaptic cell was recorded from in perforated patch-mode using gramicidin $(50 \mu \mathrm{g} / \mathrm{ml})$. No difference in the time course of synaptic depression was found in these experiments, and the data were pooled. A liquid junction potential of $11 \mathrm{mV}$ measured as described (Neher, 1992) was taken into account for all of the data. The bath was constantly perf used with fresh recording medium at a rate of $\sim 1 \mathrm{ml} / \mathrm{min}$ throughout the recording and contained (in $\mathrm{mm}$ ): $126 \mathrm{NaCl} ; 2.5 \mathrm{KCl} ; 1.25 \mathrm{NaH}_{2} \mathrm{PO}_{4}$, $2 \mathrm{MgSO}_{4}, 2 \mathrm{CaCl}_{2}, 26 \mathrm{NaHCO}_{3}, 10$ dextrose, 0.02 glycine. During recordings from inhibitory pairs, 6-cyano-7-nitroquinoxaline-2,3-dione $(\mathrm{CNQX}, 50 \mu \mathrm{M})$ and DL-2-amino-5-phosphonovaleric acid (DL-APV, 100 $\mu \mathrm{M})$ were added to the medium to block excitatory synaptic transmission. Picrotoxin $(100 \mu \mathrm{M})$ was used to block inhibitory synaptic transmission mediated via $\mathrm{GABA}_{\mathrm{A}}$ receptors. In some cultures, the application of picrotoxin resulted in abrupt, large inward currents in cells in voltage clamp probably attributable to synchronized discharges in disinhibited networks. In this case, monosynaptic excitatory synaptic transmission was studied after extensive washout of picrotoxin. In some experiments, the $\mathrm{CaCl}_{2}$ concentration was raised to $3 \mathrm{~mm}$ and the $\mathrm{MgCl}_{2}$ concentration decreased to $1 \mathrm{~mm}$. For assaying synaptic connectivity, the neuron recorded with a pipette containing the "presynaptic" solution was stimulated at a low frequency $(0.1-0.2 \mathrm{~Hz})$ by $1-3 \mathrm{msec}$ depolarizing current injections $(0.5-1.5 \mathrm{nA})$, and the response of the postsynaptic cell was monitored. Connectivity between two cells amounted to $>75 \%$ within the field of view $(\sim 300 \mu \mathrm{m})$ for cultures 3-4 weeks old. Fast-spiking interneurons were recognized morphologically as multipolar cells with relatively large, pyramidal-shaped somata and extensive dendritic arborizations with thick proximal processes, resembling parvalbuminpositive basket cells (Nitsch et al., 1990; Lee et al., 2000).

Data were collected through two amplifiers (Axopatch-1D for the presynaptic neuron and Axopatch 200B for the postsynaptic neuron; Axon Instruments) and a multichannel encoding device (Neurodata Instruments) and stored on videotape for off-line analysis. Data were acquired at $10 \mathrm{kHz}$ with an IBM Pentium computer using pClamp6 software (Axon Instruments) and low-pass filtered at $2 \mathrm{kHz}$ using a Gaussian filter. Fitting of data traces was done in Clampfit using a Chebychev fitting routine. For simplicity, the decay of postsynaptic currents was fitted with a mono-exponential curve. Decay times were not analyzed when polysynaptic responses obscured the decay of the monosynaptic response. For measurement of the paired-pulse ratio in one experiment, at least three sweeps were averaged per interpulse interval, and at least three interpulse intervals were obtained per cell pair. Fitting of data plots was done in Origin (Version 4.1). Linear regression (see Fig. 5), mono-exponential and bi-exponential curves (see Figs. 3, 4), and the Hill equation according to "steady-state depression $=(1 /(1+$ (stimulation frequency $\left.\left(f_{\text {crit }}\right)^{p}\right)$ )" (see Fig. 6) were used. The steady-state response during trains was determined as the average of 50 responses after a stimulation period equivalent to at least three time constants. For $20 \mathrm{~Hz}$ stimulation, the last 50 responses in the train were analyzed. Analysis was done blind to the genotype of the animals used for the experiments, and data are presented as mean \pm SEM. Statistical significance was assessed using paired or unpaired $t$ test as appropriate, and $p<0.05$ was considered statistically significant. All chemicals, including neurotransmitter receptor antagonists, were purchased from Sigma-RBI, except for CNQX, which was obtained from Tocris Cookson.

\section{RESULTS}

\section{Characterization of unitary IPSCs and EPSCs in culture}

Synaptic transmission between pairs of monosynaptically connected neurons in culture was examined at near physiological temperatures $\left(33.5-35^{\circ} \mathrm{C}\right)$. The main goals of this investigation were (1) to define the stimulation protocols necessary to induce synaptic depression with properties consistent with presynaptic depletion of vesicles and (2) to investigate whether with these stimulation parameters synaptic transmission between neurons derived from SJ1-deficient animals was compromised. As described below, this initial characterization revealed that at inhibitory synapses two distinct phases of synaptic depression coexisted that were temporally separated and appeared suited to search for deficits associated with the lack of SJ1.

Cultured cortical neurons were used because these showed at least two advantages over acute preparations. First, by culturing neurons from neonatal mice and allowing differentiation in vitro, we circumvented the possibility that decreased maintenance of synaptic transmission could be a secondary consequence of genetic deletion of SJ1 on the general health of the mice (Cremona et al., 1999). Second, the high connectivity between cells resulted in paired recordings with comparatively large evoked responses in the postsynaptic neuron (see below). Accordingly, a finite amplitude of postsynaptic response size was retained even during prolonged stimulation and allowed us to track the full temporal development of the depression.

Synaptic transmission was characterized between pairs of neurons via the whole-cell patch-clamp recording technique. Figure 1 illustrates the basic properties of unitary wild-type (wt) connections obtained at a stimulation frequency of $0.2 \mathrm{~Hz}$ in $\left[\mathrm{Ca}^{2+}\right]_{\mathrm{ex}}=$ $\left[\mathrm{Mg}^{2+}\right]_{\mathrm{ex}}=2 \mathrm{~mm}$. Presynaptic neurons were identified by the characteristics of action potential discharge in response to brief (120 msec) depolarizing current injections in the current-clamp recording mode. Two categories of neurons with distinct firing properties were found. The first category, identified as inhibitory neurons (see below), responded with action potentials with a 
A

B
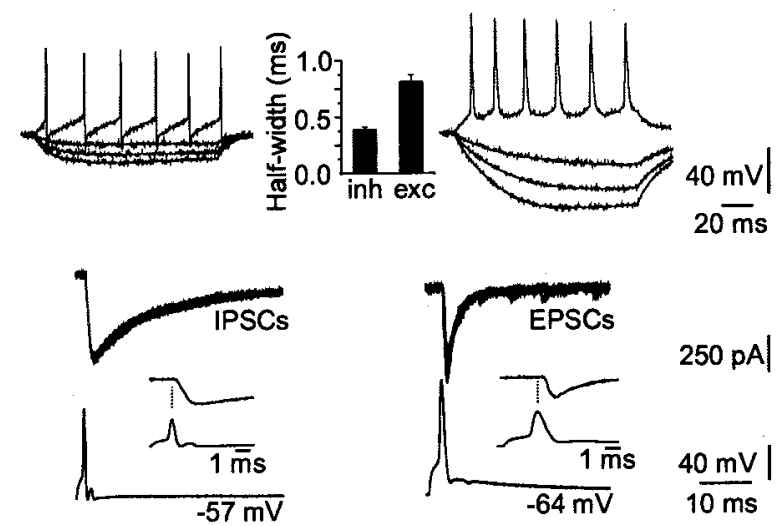

C

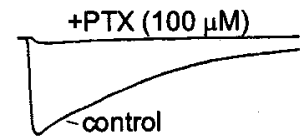

D

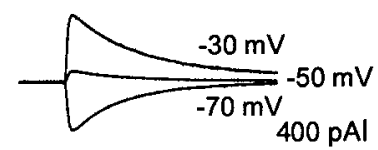

$E$

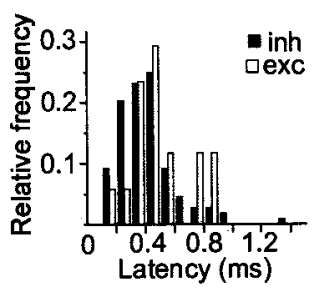

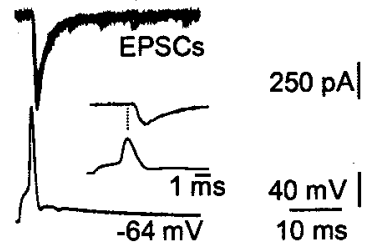

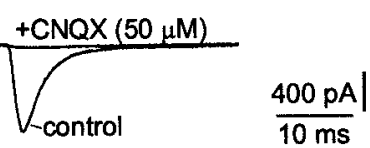

$\overline{10 \mathrm{~ms}}$

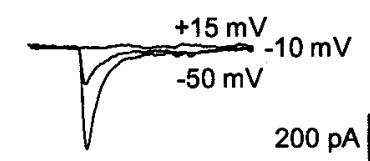

$F$
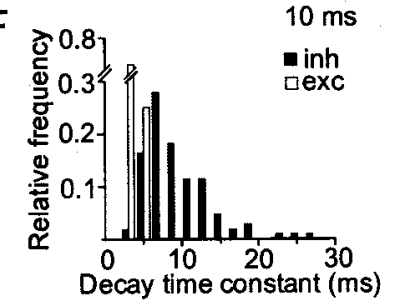

Figure 1. Characterization of the synaptic connections formed by neuronal cell pairs in culture. $A$, Action potential discharge patterns of an inhibitory (left) versus an excitatory (right) neuron. Cellular responses to square current injections (120 msec, amplitudes of $-300,-200,-100$, and $+200 \mathrm{pA}$ ) are displayed. Resting membrane potentials were -57 and -58 $\mathrm{mV}$ for inhibitory and excitatory neuron, respectively. Inset shows average half-width of single action potentials elicited by a brief $(3 \mathrm{msec})$ depolarizing current injection $[n=36$ for inhibitory (inh) neurons; $n=18$ for excitatory (exc) neurons]. No difference was found for the properties of action potentials of wt and SJ1-ko animals (see Results), and the data were pooled. $B-D$, Characterization of unitary synaptic responses between inhibitory (left panels) and excitatory (right panels) synapses of cultured cell pairs. $B$, Unitary IPSCs (same presynaptic cell as in $A$ ) or EPSCs (presynaptic cell different from $A$ ), with single presynaptic action potentials and indication of resting membrane potentials shown on the bottom, and 10 overlaid postsynaptic responses shown on the top. Holding potential of postsynaptic neurons was $-70 \mathrm{mV}$ in both cases. Insets illustrate expanded portions of a single action potential and the corresponding postsynaptic response (calibration: $1 \mathrm{msec}$; no calibration for vertical axis). Dotted line runs from the peak of the presynaptic action potential to the postsynaptic response. $C$, Pharmacological identification of postsynaptic potentials (different cells from $A$ and $B$ ). IPSCs and EPSCs were blocked by picrotoxin $(100 \mu \mathrm{M})$ and CNQX $(50 \mu \mathrm{M})$, respectively. The effect of CNQX was fully reversible; the effect of PTX was partially reversible after 15-20 min washout (data not shown). $D$, Reversal potentials of IPSCs (left) and EPSCs (right). Holding potential is indicated next to the traces. Different pairs from $A-C$. E, Histogram of latencies from the peak of the presynaptic action potentials to the onset of the postsynaptic potential in inhibitory (closed columns) and excitatory (open columns) pairs. Data were pooled from wt and SJ1-ko pairs and binned in $0.1 \mathrm{msec}$ intervals $(n=68 \mathrm{wt}+41 \mathrm{SJ} 1$-ko for inhibitory pairs; $n=13 \mathrm{wt}+5 \mathrm{SJ} 1$-ko for excitatory pairs). $F$, Histogram of the decay times of postsynaptic responses measured by a mono-exponential fit from the peak of the postsynaptic potentials. Data were pooled from wt and SJ1-ko pairs ( $n=64 \mathrm{wt}+40 \mathrm{SJ} 1$-ko for inhibitory pairs; $n=11 \mathrm{wt}+5$ $\mathrm{SJ} 1-\mathrm{ko}$ for excitatory pairs) and binned in $2 \mathrm{msec}$ intervals.

narrow half-width $(0.41 \pm 0.02 \mathrm{msec} ; n=23$ representative cases $)$ (Fig. $1 A$, inset), a large, rapid afterhyperpolarization (amplitude was $15-36 \mathrm{mV}$, measured from action potential threshold to the peak of the afterhyperpolarization), and no detectable frequency adaptation. The second category, consisting of excitatory neurons (see below), displayed action potentials with a half-width of $0.81 \pm 0.08 \mathrm{msec}(n=13)$ (Fig. $1 A$, inset) and frequency adaptation starting between the second and third action potential (Fig. $1 A)$. Infrequently $(<1 \%)$, neurons were found that discharged in doublets or bursts instead of spiking regularly, and these were not examined further. Inhibitory fast-spiking neurons were selected as postsynaptic cells based on morphological appearance (see Materials and Methods). Action potential discharge was not monitored in these cells, because of the presence of the $\mathrm{Na}^{+}$channel blocker QX-314 (1 mM) in the patch pipette solution.

Monosynaptic connections were recognized by the short latency between the peak of the action potential in the presynaptic neuron (evoked by $1-3 \mathrm{msec}, 0.5-1.5 \mathrm{nA}$ current injections) and the onset of the postsynaptic current response obtained in voltage clamp around $-70 \mathrm{mV}$. The mean latency determined in this manner was $0.40 \pm 0.02 \mathrm{msec}$ for inhibitory neurons $(n=68)$ and $0.45 \pm 0.05 \mathrm{msec}$ for excitatory neurons $(n=13)$, with values covering similar ranges (Fig. $1 B$, insets, $E$ ). These values were smaller than those obtained for polysynaptic connections $(>2$ msec; $n=5 ; p<0.001)$. Moreover, synaptic communication occurred without failures at stimulation frequencies $>5 \mathrm{~Hz}$ between monosynaptically but not between polysynaptically connected pairs (data not shown).

Unitary synaptic responses in the postsynaptic cell were unambiguously identified as IPSCs or EPSCs on the basis of pharmacology, reversal potential, and kinetics (Fig. $1 B-D, F$ ). Fastspiking, nonadapting cells always generated IPSCs, whereas regularly spiking, adapting cells invariably produced EPSCs. IPSCs and EPSCs around $-70 \mathrm{mV}$ were rapidly blocked $(>95 \%)$ by bath application of picrotoxin (PTX, $0.1 \mathrm{~mm}$ ) and CNQX (50 $\mu \mathrm{M}$ ), respectively (Fig. $1 C$ ), indicating that they were mediated by $\mathrm{GABA}_{\mathrm{A}}$ receptors and by non-NMDA glutamatergic receptors around $-70 \mathrm{mV}$. The mean unitary IPSC amplitude was $-325 \pm$ $29 \mathrm{pA}(n=68)$ at a holding potential of $-70 \mathrm{mV}$; the mean EPSC amplitude was $-665 \pm 137 \mathrm{pA}(n=13)$. The reversal potential of IPSCs was $-50.6 \pm 1.2 \mathrm{mV}$ (measured in $n=36$ cells), close to the expected reversal potential for $\mathrm{Cl}^{-}$ions $(-56 \mathrm{mV})$. This gives a unitary peak conductance change for IPSCs of $15.6 \pm 1.9 \mathrm{nS}$ at $-70 \mathrm{mV}$. In contrast, EPSCs did not reverse at negative holding potentials $(n=7)$ (Fig. $1 D)$. Mono-exponential fits to the decaying phase of the postsynaptic currents yielded values of $\tau=8.6 \pm$ $0.5 \mathrm{msec}(n=64)$ for the IPSCs and $\tau=3.7 \pm 0.3 \mathrm{msec}(n=11)$ for the EPSCs, with IPSCs decaying distinctly more slowly than EPSCs (Fig. $1 F$ ). A further characteristic feature of inhibitory connections in culture was their low variability. The coefficient of variation of $8-10$ response amplitudes was $5.2 \pm 0.8 \%(n=33)$, whereas it lay routinely above $10 \%$ for EPSCs (average $12.0 \pm$ $2.3 \% ; n=9 ; p<0.005)$. Moreover, failures of evoked release were not observed in any of the connected inhibitory pairs studied [ $n=68$ wt pairs and 41 SJ1-knock-out (SJ1-ko) pairs].

No substantial differences in the above-mentioned basic properties of synaptic transmission were found when neurons derived from SJ1-knock-out animals were studied in culture. The data from these animals were therefore included in the histograms in Figure $1 A, E, F$. These included action potential width (inhibitory neurons $0.37 \pm 0.03 \mathrm{msec} ; n=13$ representative cases; excitatory neurons $0.83 \pm 0.09 \mathrm{msec} ; n=5$ ), the latency to onset of the 
postsynaptic response (inhibitory neurons $0.41 \pm 0.04 \mathrm{msec} ; n=$ 41; excitatory pairs $0.48 \pm 0.13 \mathrm{msec} ; n=5$ ), the amplitude of evoked responses (mean amplitude for inhibitory neurons $-364 \pm 39 \mathrm{pA} ; n=41$; for excitatory neurons $-663 \pm 243 \mathrm{pA}$; $n=6)$, the reversal potential and peak synaptic conductance change for IPSCs $(-51.3 \pm 1.8 \mathrm{mV} ; 15.1 \pm 2.1 \mathrm{nS} ; n=18)$, and decay characteristics of the postsynaptic response (mean for inhibitory pairs $10.8 \pm 0.8 \mathrm{msec} ; n=40$; for excitatory pairs: $4.0 \pm$ $0.4 \mathrm{msec} ; n=5$ ). These results suggest that synapse formation and the structural basis for low-frequency synaptic transmission in culture developed normally in the absence of SJ1.

\section{Enhanced stability of IPSCs versus EPSCs during repetitive stimulation}

Differences between inhibitory and excitatory transmission were also apparent with prolonged stimulation, as described previously for acute preparations (Fig. 2) (Galarreta and Hestrin, 1998; Varela et al., 1999). When exposed to a train of 1000 action potentials at $10 \mathrm{~Hz}$, excitatory pairs showed EPSCs the amplitude of which steadily decayed over the period of stimulation (Fig. $2 A$, bottom two panels). In contrast, the amplitude of unitary IPSCs decayed rapidly during the first 10 action potentials, but these synapses then maintained response size to a large extent for the rest of the stimulation, as indicated by the comparable size of the responses displayed in the middle (490-500) and at the end (990-1000) of the train (Fig. 2A, top two panels). A plot of the pooled data in Figure $2 B$ illustrates the full time course of depression of inhibitory and excitatory synaptic transmission for 1000 action potentials delivered at $10 \mathrm{~Hz}(n=16$ for inhibitory pairs; $n=3$ for excitatory pairs). This reveals that inhibitory transmission decayed to $\sim 55 \%$ of the initial response within the first 10 stimuli, but then this rapid decay was halted and response size largely maintained, leveling off to $\sim 40 \%$ of the initial amplitude. In contrast, excitatory responses, although decaying more slowly at the beginning of the stimulation period, decremented progressively to $<20 \%$ of the response (significantly different from level reached by inhibitory pairs; $p<0.01$ ). During these prolonged stimulation periods, the amplitude of the presynaptic action potential in the inhibitory neuron remained unchanged $(62.5 \pm 2.8 \mathrm{mV}$ for the first 10 action potentials vs $61.4 \pm 3.5 \mathrm{mV}$ for the last 10 action potentials; $p>0.05)$, and the half-width increased by $\sim 10 \%(0.42 \pm 0.02 \mathrm{msec}$ vs $0.46 \pm 0.04 \mathrm{msec} ; p<$ $0.05)$. For excitatory connections, neither the amplitude of the action potentials $(53.3 \pm 3.2 \mathrm{mV}$ vs $46.3 \pm 3.4 \mathrm{mV})$ nor the half-width $(1.1 \pm 0.19 \mathrm{msec}$ vs $1.02 \pm 0.21 \mathrm{msec})$ changed significantly $(p>0.05)$. Therefore, use-dependent alterations in somatic action potential waveform were not directly correlated with the extent of synaptic depression at these terminals.

Synaptic depression expressed by fast-spiking GABAergic neurons in cortical cultures therefore occurred on two temporally distinct scales: a fast process led to immediate partial depression of the response, whereas a weaker, slowly developing depression appeared in a second phase. The depression induced by this prolonged stimulation was largely reversible (see below). In contrast, synaptic depression at excitatory connections appeared to be a gradual process with a progressive decrease in response, likely caused by temporally overlapping mechanisms. The characteristic development of inhibitory synaptic depression suggests that at least two, temporally separate mechanistic processes were involved.
A
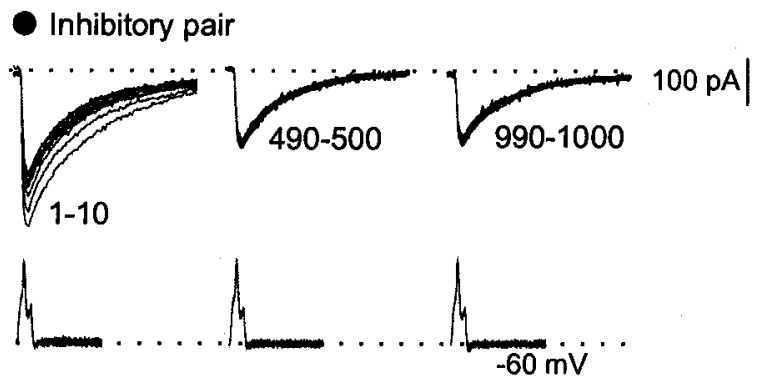

O Excitatory pair

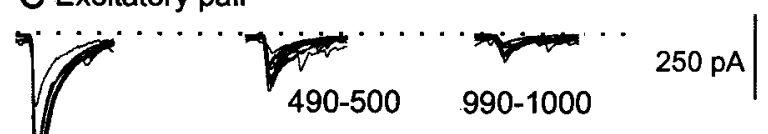

B
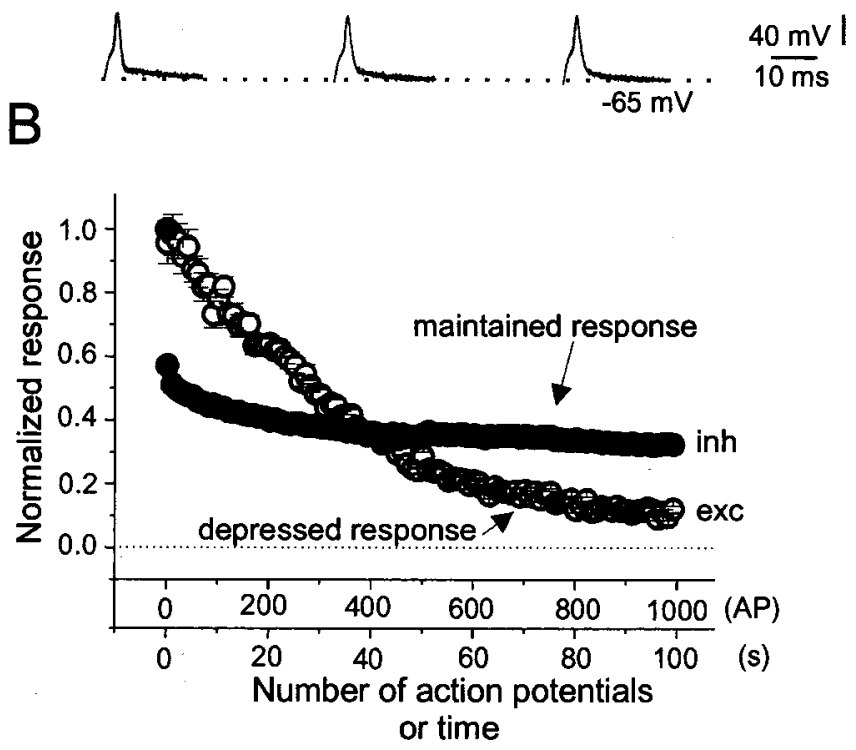

Figure 2. Time course of synaptic depression of inhibitory and excitatory unitary synaptic connections during application of 1000 stimuli at $10 \mathrm{~Hz}$ to the presynaptic cell. $A$, Selected postsynaptic responses obtained from an inhibitory (top two lines) and excitatory (bottom two lines) pair, with corresponding presynaptic action potentials shown below. Responses to stimuli $1-10,490-500$, and 990-1000 of the train are shown superimposed. The responses to action potentials 990-1000 did not change appreciably compared with responses 490-500 in the inhibitory pair, whereas they were markedly smaller in the excitatory pair. All data were obtained from wt cultures. Holding potential of postsynaptic neurons was $-70 \mathrm{mV} . B$, Pooled data illustrating the full time course of depression of unitary postsynaptic currents in response to sustained activation at $10 \mathrm{~Hz}$ in inhibitory $(n=16,0)$ and excitatory $(n=3, \bigcirc)$ wt pairs. Data were normalized to the postsynaptic response amplitude during a preceding baseline of 10 responses obtained via stimulation at $0.2 \mathrm{~Hz}$. Each symbol represents the average of 10 consecutive postsynaptic currents. Note initial stronger depression of IPSCs, followed by a maintained response ( $\sim 40 \%$ of control, long arrow). In contrast, excitatory synapses undergo gradual depression to $\sim 11 \%$ of the initial amplitude (short arrow). Top abscissa depicts the number of presynaptic action potentials in the train; bottom abscissa marks the time during the train.

\section{Rapid depression induced by paired-pulse stimulation}

We further characterized the two temporally separate processes controlling inhibitory synaptic depression and then determined the consequences of SJ1 deletion on these processes. The rest of 


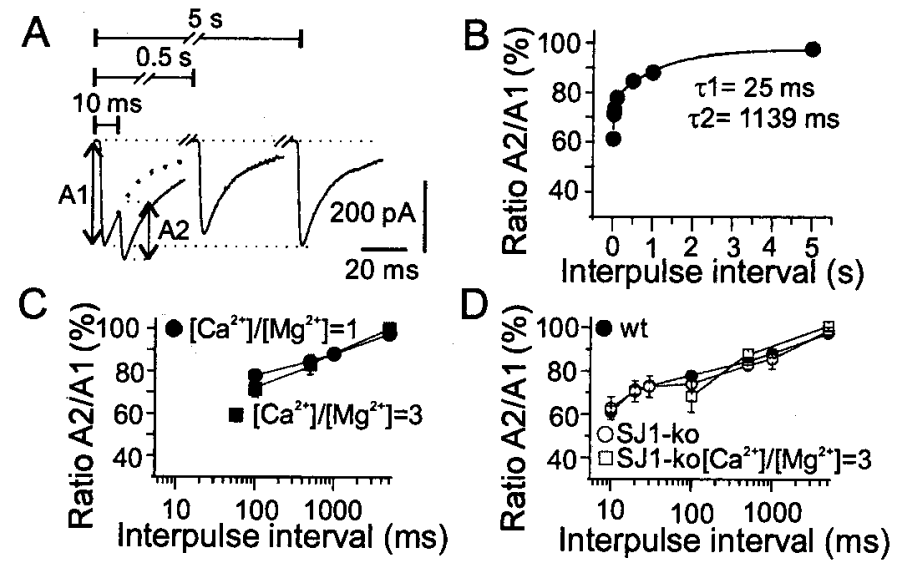

Figure 3. Paired-pulse depression of inhibitory synaptic transmission in cortical culture. $A$, Unitary responses of a wt neuron to paired stimuli delivered at interstimulus intervals of $10 \mathrm{msec}, 500 \mathrm{msec}$, and $5 \mathrm{sec}$ to the synaptically coupled presynaptic neuron (average of 3 sweeps for each interpulse interval). $A 1$ and $A 2$ denote amplitudes used for evaluation of paired-pulse ratio $(A 2 / A 1)$. Bold dotted line shows decay of first IPSC in the absence of a second stimulus. Progressing decay of the first IPSC at the peak of the second IPSC was taken into account in the measurement of $A 2$ ( fine short dotted lines). B, Plot of paired-pulse ratio (A2/A1) versus duration of interpulse interval. For every interpulse interval, $n \geq 13$ cell pairs. Ordinate in the plot shown starts at a paired-pulse ratio of $30 \%$ to facilitate display of recovery kinetics. $C$, Paired-pulse ratio at interpulse intervals $\geq 100 \mathrm{msec}$ (i.e., $100 \mathrm{msec}, 500 \mathrm{msec}, 1 \mathrm{sec}, 5 \mathrm{sec}$ ) was not altered when the extracellular concentrations of $\mathrm{Ca}^{2+}$ and $\mathrm{Mg}^{2+}$ were changed from $\left.2 \mathrm{~mm} / 2 \mathrm{~mm}\left(\mathrm{Ca}^{2+}\right] /\left[\mathrm{Mg}^{2+}\right]=1\right)$ to $3 \mathrm{~mm} / 1 \mathrm{~mm}\left(\mathbf{\square} / \mathrm{Ca}^{2+}\right] /$ $\left.\left[\mathrm{Mg}^{2+}\right]=3\right) ;(n \geq 4 ; p>0.05$ for all data points). $D$, Paired-pulse ratio for wt $(\bullet, n \geq 13$ per data point) and SJ1-ko inhibitory pairs $(\bigcirc, n \geq 6$ per data point) for $\left[\mathrm{Ca}^{2+}\right] /\left[\mathrm{Mg}^{2+}\right]=2 \mathrm{~mm} / 2 \mathrm{~mm}$. The two curves were not significantly different $(p>0.05)$. $\square$ represents paired-pulse ratio for SJ1-ko pairs in $\left[\mathrm{Ca}^{2+}\right] /\left[\mathrm{Mg}^{2+}\right]=3 \mathrm{~mm} / 1 \mathrm{~mm}\left(\left[\mathrm{Ca}^{2+}\right] /\left[\mathrm{Mg}^{2+}\right]=3\right)$. Data were not significantly different from wt and SJ1-ko neurons for $\left[\mathrm{Ca}^{2+}\right] /$ $\left[\mathrm{Mg}^{2+}\right]=1$ ( $\mathrm{n} \geq 4$ per data point; $p>0.05$ for all intervals).

this study therefore focused on paired recordings involving inhibitory, fast-spiking presynaptic neurons, performed in the continuous presence of antagonists of glutamatergic receptors (CNQX $50 \mu \mathrm{M}$, DL-APV $100 \mu \mathrm{M}$ ) in the bathing solution. First, rapid depression in inhibitory pairs was investigated by delivering paired stimuli separated by intervals of between 10 and $5000 \mathrm{msec}$ to the presynaptic neuron (Fig. $3 A$ ). The amplitude of the second IPSC $(A 2)$ was always smaller than that of the first $(A 1)$, indicating the presence of PPD. The paired-pulse ratio $(A 2 / A 1)$ was smallest for the shortest interpulse interval applied $(10 \mathrm{msec}$; $61.3 \pm 2.7 \% ; n=17)$. For longer interpulse intervals, PPD was less pronounced, and the second response equaled the size of the first after $5 \mathrm{sec}$. This recovery proceeded with a time course best described by two time constants, $\tau_{1}=25 \pm 26 \mathrm{msec}$ and $\tau_{2}=$ $1139 \pm 747 \mathrm{msec}$ (Fig. $3 B)(n \geq 13$ cell pairs per interpulse interval).

To determine whether PPD was dependent on the probability of GABA release, we investigated whether augmenting $\mathrm{Ca}^{2+}$ influx led to an enhancement of PPD. PPD was determined for $\left[\mathrm{Ca}^{2+}\right]_{\mathrm{ex}}=\left[\mathrm{Mg}^{2+}\right]_{\mathrm{ex}}=2 \mathrm{~mm}$ and then for $\left[\mathrm{Ca}^{2+}\right]_{\mathrm{ex}}=3 \mathrm{mM}$ and $\left[\mathrm{Mg}^{2+}\right]_{\mathrm{ex}}=1 \mathrm{~mm}$ (threefold increase in $\left[\mathrm{Ca}^{2+}\right] /\left[\mathrm{Mg}^{2+}\right]$ ratio). This resulted in a significant enhancement of the amplitude of the first IPSC (from $-216 \pm 31 \mathrm{pA}$ to $-293 \pm 23 \mathrm{pA} ; n=6 ; p<$ $0.005)$, suggesting that the release of GABA was enhanced. Changes in PPD induced by increasing the $\left[\mathrm{Ca}^{2+}\right] /\left[\mathrm{Mg}^{2+}\right]$ ratio were analyzed for stimuli separated by $\geq 100 \mathrm{msec}$, at which the waveforms of the two IPSCs did not overlap. At these time intervals, PPD remained unaffected (Fig. $3 C)(n \geq 4$ per data point; $p>0.05$ ). These data suggest that release-independent presynaptic processes may control the generation of PPD at interpulse intervals between $100 \mathrm{msec}$ and $5 \mathrm{sec}$, and postsynaptic factors could also contribute (see Discussion).

\section{Paired-pulse depression at SJ1-deficient inhibitory synapses}

The properties of PPD were determined from recordings between SJ1-ko cell pairs (Fig. 3D). PPD for these synapses was indistinguishable from PPD of wt pairs at all intervals tested ( $\mathrm{n} \geq 6$ per data point; $p>0.05$ ). Furthermore, PPD remained unchanged when external divalent cation concentration ratios were increased threefold for interpulse intervals $\geq 100 \mathrm{msec}$ (Fig. 3D) $(n \geq 4 ; p>$ $0.05)$. Therefore, the deletion of SJ1 appeared to leave intact basic properties of GABAergic synaptic transmission, including the dependence of release over the range of $\left[\mathrm{Ca}^{2+}\right] /\left[\mathrm{Mg}^{2+}\right]$ ratios tested, and the time dependence of responsiveness to two stimuli in short succession, likely involving transiently decreased vesicle liberation from presynaptic release sites (Kraushaar and Jonas, 2000).

\section{Synaptic depression induced by prolonged trains of stimulation}

The lack of SJ1 may manifest electrophysiologically only on time scales on which substantial vesicular recycling could occur (Cremona et al., 1999). We therefore characterized next the time course of inhibitory synaptic depression during $2-20 \mathrm{~Hz}$ trains of 1000 presynaptic stimuli at wt pairs. This protocol leads to ongoing GABA release for $50-500 \mathrm{sec}$, a time window covering the duration of vesicular cycles (for review, see Ryan, 1996; Neher, 1998). Figure $4 A$ shows the time course of synaptic depression evoked with stimulation at 2,10 , and $20 \mathrm{~Hz}$. A rapidly initiating depression occurred over the first few stimuli (Fig. 2). A slower depression followed that developed for stimulation frequencies at 10 and $20 \mathrm{~Hz}$ but was not evident at $2 \mathrm{~Hz}$ over the time course studied. Thus, stimulation at $2 \mathrm{~Hz}$ induced an initial rapid decrement of IPSC amplitude to $74.7 \pm 1.7 \%$ of control amplitude after 10 stimuli, after which the IPSC amplitude did not change significantly for the remaining 990 pulses (Fig. $4 A, B)(n=8 ; p>$ $0.05)$. In contrast, depression increased considerably from the 10th to the 1000th action potential when stimuli were delivered at frequencies of 10 or $20 \mathrm{~Hz}$ (Fig. $4 A, B$ ) or reached undetectable amplitudes at $100 \mathrm{~Hz}$ (data not shown). The steady-state IPSC amplitude (see Materials and Methods) was $74.5 \pm 0.3 \%$ of baseline for $2 \mathrm{~Hz}(n=8), 35.3 \pm 0.1 \%$ for $10 \mathrm{~Hz}(n=16)$, and $23.2 \pm 0.2 \%$ for $20 \mathrm{~Hz}(n=3)$ (Figs. $4 B, 6 C$ ).

The dual time course of depression was characterized by fitting exponential curves to the data. Rapid depression was quantified by mono-exponential fitting to the first 25 responses in the train, after which an intermediary plateau of depression was reached (Fig. $4 C$ ). This yielded time constants of $0.73 \pm 0.08,0.16 \pm 0.01$, and $0.08 \pm 0.01 \mathrm{sec}$ for 2,10 , and $20 \mathrm{~Hz}$ stimulations, respectively. When evaluated in number of stimuli, these three decay constants amounted to $1.46 \pm 0.2,1.61 \pm 0.1$, and $1.70 \pm 0.12$ action potentials. Thus, for stimulation frequencies between 2 and 20 $\mathrm{Hz}$, a rapid depression developed within a comparable number of stimuli (Fig. 4C, inset) (Jensen et al., 1999). Subsequent fitting of the time course of slow depression for 10 and $20 \mathrm{~Hz}$ yielded decay constants of $22.3 \pm 0.7$ and $33.3 \pm 1.8 \mathrm{sec}$, respectively, equivalent to $223 \pm 7$ and $666 \pm 36$ presynaptic action potentials. Thus, stimulation at higher frequencies induced a slow depression over 
A

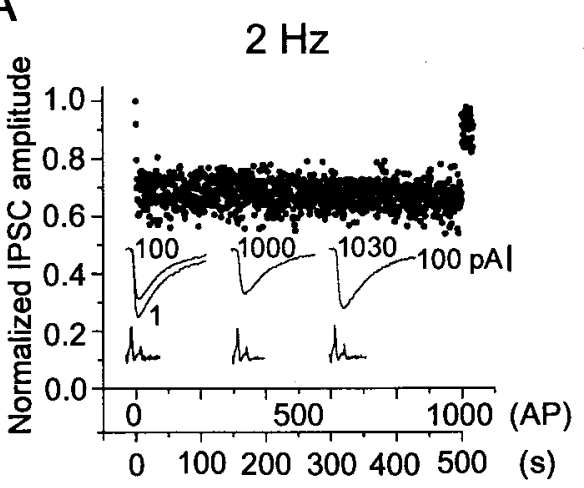

B

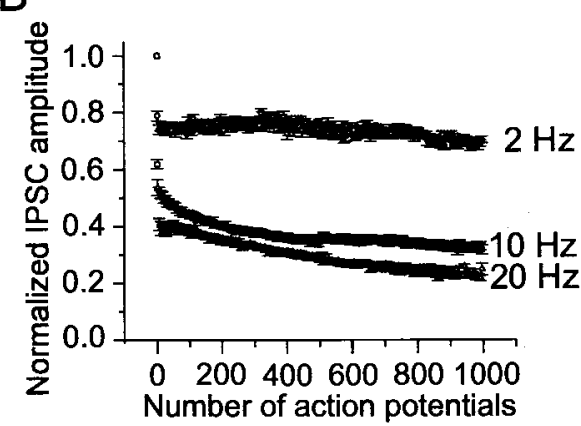

$10 \mathrm{~Hz}$

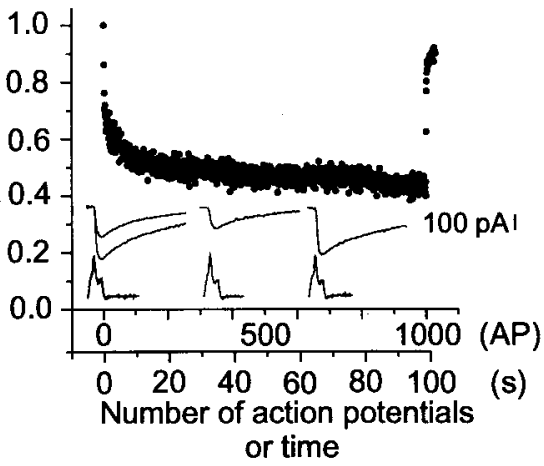

C

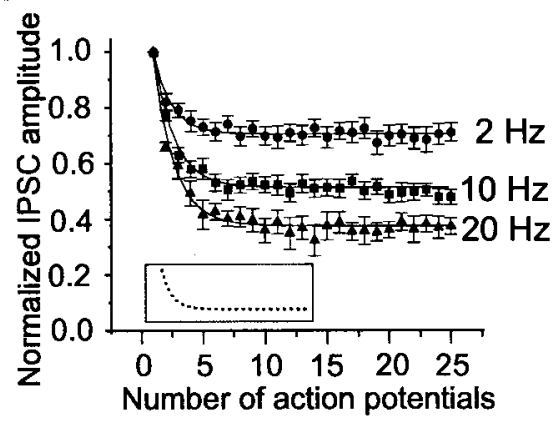

$20 \mathrm{~Hz}$

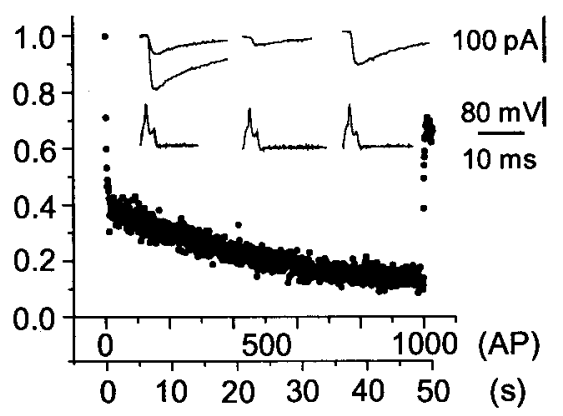

D

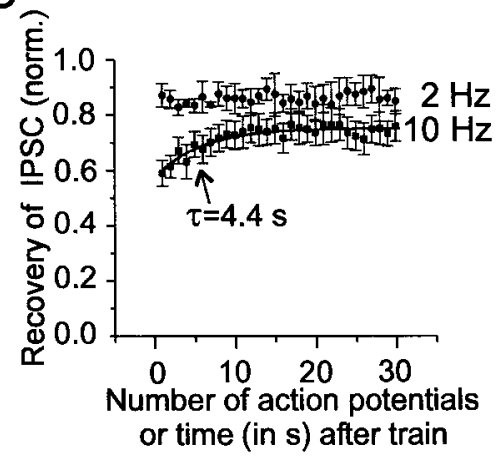

Figure 4. Slow frequency-dependent depression of inhibitory synapses in culture. $A$, Representative responses from three different pairs stimulated 1000 times at 2 (left), 10 (middle), or 20 (right) Hz. IPSCs were normalized to the baseline amplitude obtained from 10 responses during preceding stimulation at $0.2 \mathrm{~Hz}$. Synaptic depression was characterized by a rapid phase of decay within $\sim 10$ stimuli, followed by a slower decay. The amplitude of the slow decay was increasingly prominent at higher stimulation frequencies. All of the 1000 responses of the train are plotted as single points. Recovery from depression was assessed by 30 pulses at $1 \mathrm{~Hz}$, starting $1 \mathrm{sec}$ after the end of the train (action potentials 1001-1030). Action potentials and IPSCs from the 1st, 100th, 1000th, and 1030th action potential are displayed in the inset at all three stimulation frequencies. Top abscissa shows number of action potentials in the train and during recovery; bottom abscissa shows time during the train. Axis titles hold for all three graphs. $B$, Averaged waveforms of synaptic depression induced by 1000 stimuli applied at $2(n=8), 10(n=16)$, or $20(n=3) \mathrm{Hz}$. Averages of five consecutive (average starting with the second response) responses are displayed as single points. Steady-state amplitude decreased with increasing stimulation frequency. $C$, Plot of the first 25 responses in the train. Inset shows an overlay of the normalized mono-exponential curves fitted to the three datasets. The time course of fast synaptic depression was not dependent on frequency (see Results). $D$, Recovery from synaptic depression assessed with single stimuli delivered at $1 \mathrm{~Hz}$, starting $1 \mathrm{sec}$ after the end of the train. For the train at $2 \mathrm{~Hz}$, recovery was complete with the first response after the train $(n=4)$. For $10 \mathrm{~Hz}$, recovery showed a slowly relaxing component, with a time constant of $4.4 \pm 0.7 \mathrm{sec}(n=9$; arrow $)$.

hundreds of action potentials, similar to the slow depression described previously for basket cells in dentate gyrus (Kraushaar and Jonas, 2000).

Recovery from synaptic depression was assessed by decreasing the stimulation rate to $1 \mathrm{~Hz}$ starting $1 \mathrm{sec}$ after the end of the train (Fig. 4A,D). This stimulation frequency was chosen to obtain a time resolution of recovery of $1 \mathrm{sec}$. However, it should be taken into account that $1 \mathrm{~Hz}$ stimulation per se induced a depression to $\sim 80 \%$ of the baseline response at $0.2 \mathrm{~Hz}(n=15$; data not shown), possibly leaving undetected very slow recovery phases toward undepressed response amplitudes (Kraushaar and Jonas, 2000). Depression induced by $2 \mathrm{~Hz}$ stimulation recovered to $87.1 \pm 4.3 \%$ of the original response within $1 \mathrm{sec}$, indicating completion of recovery to a level not significantly different from steady-state depression at $1 \mathrm{~Hz}(n=4 ; p>0.05)$. Trains induced by stimulation at 10 and $20 \mathrm{~Hz}$, in contrast, showed an additional slow recovery process during the $1 \mathrm{~Hz}$ stimulation. For a preceding train at $10 \mathrm{~Hz}$, a slow recuperation of the amplitude progressed with a time constant of $4.4 \pm 0.7 \mathrm{sec}(n=9)$ (Fig. 4D). This slow phase of recovery appeared to be linked to the previous development of slow depression. Thus, recovery from depression did not display a slow component after $10-100 \mathrm{~Hz}$ trains containing 10 stimuli only and was complete within $1 \mathrm{sec}$ (data not shown), but a slow phase of recovery ( $>3 \mathrm{sec}$ ) was induced after eliciting a train of 500 action potentials ( $n=3$; data not shown). Recovery at higher frequencies, in particular 20 and $100 \mathrm{~Hz}$, was variable and proceeded partially (Fig. $4 A$, right panel), suggesting the possibility that long-term effects on synaptic transmission occurred because of prolonged stimulation at these higher frequencies. Recovery at $20 \mathrm{~Hz}$ and higher frequencies was therefore not included in the evaluation of slow recovery processes associated with slow depression. Altogether, this investigation revealed a slow phase of recovery characterized by a time constant of $\sim 4$ sec that appeared to be coupled to the previous induction of a slow component of depression (Galarreta and Hestrin, 1998; Kraushaar and Jonas, 2000).

Slow synaptic depression has been proposed to result from depletion of the readily releasable pool (RRP) and involvement of "reserve" vesicular pools not normally recruited during low levels of activity (Ceccarelli and Hurlbut, 1980; Zucker, 1989; Pieribone et al., 1995; von Gersdorff and Matthews, 1997; Neher 1998; Wu and Betz, 1998; Jensen et al., 1999; Delgado et al., 2000; 
A

- $\left[\mathrm{Ca}^{2+}\right] /\left[\mathrm{Mg}^{2+}\right]=1$

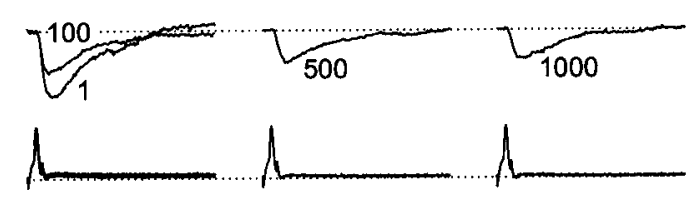

$\left[\mathrm{Ca}^{2+}\right] /\left[\mathrm{Mg}^{2+}\right]=3$

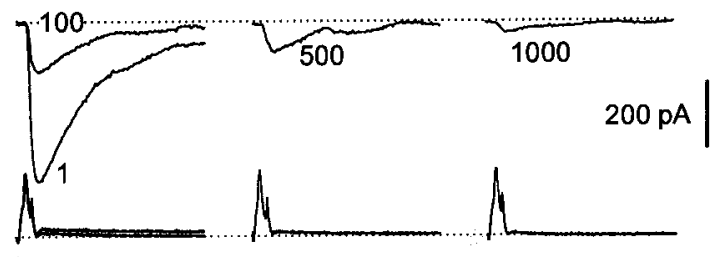

$40 \mathrm{mVl}$

B

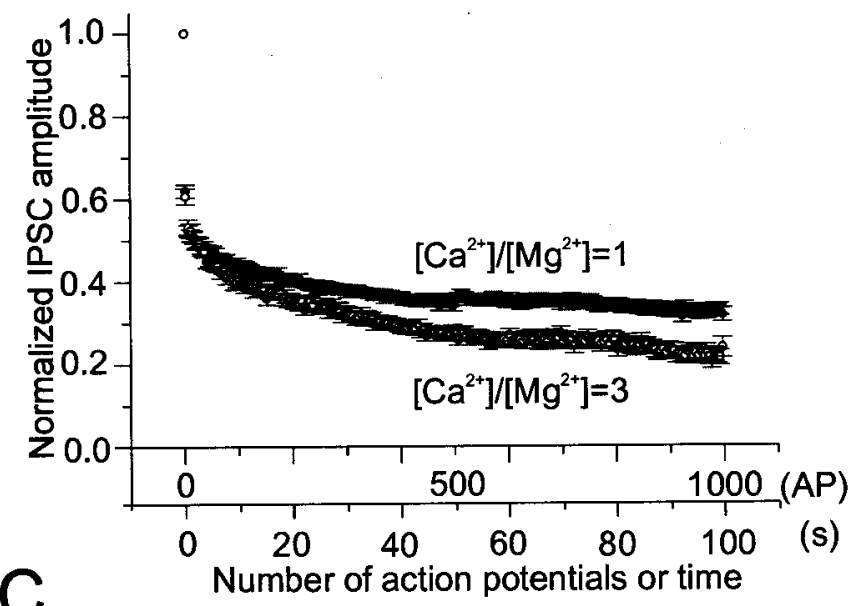

1

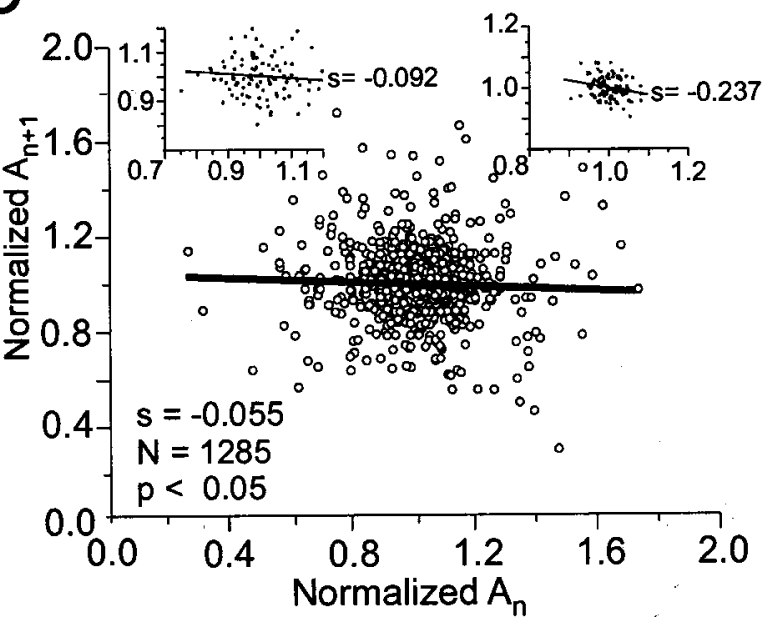

Figure 5. Dependence of slow synaptic depression on the extracellular $\left[\mathrm{Ca}^{2+}\right] /\left[\mathrm{Mg}^{2+}\right]$ ratio. $A$, Selected responses $(1,100,500$, and 1000 of the train) of a cell to a $10 \mathrm{~Hz}$ train with 1000 stimuli in the presence of $\left[\mathrm{Ca}^{2+}\right] /\left[\mathrm{Mg}^{2+}\right]=2 \mathrm{~mm} / 2 \mathrm{mM}$, and after exchange to a bathing solution containing $\left[\mathrm{Ca}^{2+}\right] /\left[\mathrm{Mg}^{2+}\right]=3 \mathrm{~mm} / 1 \mathrm{mM}$. This led to increased depression of response amplitudes during the train. $B$, Pooled data illustrating increased depression in $\left[\mathrm{Ca}^{2+}\right] /\left[\mathrm{Mg}^{2+}\right]=3 \mathrm{~mm} / 1 \mathrm{~mm}\left(\left[\mathrm{Ca}^{2+}\right] /\left[\mathrm{Mg}^{2+}\right]=3\right.$; $n=6)$ as opposed to $\left[\mathrm{Ca}^{2+}\right] /\left[\mathrm{Mg}^{2+}\right]=2 \mathrm{~mm} / 2 \mathrm{mM}\left(\left[\mathrm{Ca}^{2+}\right] /\left[\mathrm{Mg}^{2+}\right]=1\right.$; $n=16$ ). Averages of five consecutive (average starting with the second response) responses are displayed as single points. Depression levels differed significantly starting from the averaged response to action potentials 107-112. $C$, Correlation of peak IPSC amplitudes in the late portion
Kraushaar and Jonas, 2000). We therefore asked whether the slow depression observed at higher stimulation frequencies showed properties expected from a vesicular depletion process. First, if an RRP was depleted during repetitive stimulation, the extent of depletion would depend in part on the average release probability. Synaptic depression induced by prolonged stimulation was therefore compared for two different ratios of extracellular $\left[\mathrm{Ca}^{2+}\right] /\left[\mathrm{Mg}^{2+}\right]$ (Fig. 5A). When this ratio was increased from 1 to 3 (Fig. 3), rapid depression during the first $\sim 100$ stimuli was unchanged but then followed by an enhanced amplitude of slow depression ( $p<0.05$ for data points after stimulus number 106) (Fig. $5 B$ ). The steady-state response amplitude of the train was significantly smaller in $3 \mathrm{~mm}\left[\mathrm{Ca}^{2+}\right] / 1 \mathrm{~mm}\left[\mathrm{Mg}^{2+}\right]$ (Fig. $5 B$ ) (25.8 $\pm 0.1 \%$ of initial amplitude, $n=6$, vs $35.3 \pm 0.1 \%$ of initial amplitude, $n=16 ; p<0.001)$. Thus, increased release probability induced an enhancement of slow depression.

Next, we investigated whether amplitudes of consecutive IP$\mathrm{SCs}$ in the second portion of the train were correlated, such that a comparatively large IPSC would be followed preferentially by a smaller IPSC (Debanne et al., 1996; Kraushaar and Jonas, 2000; Matveev and Wang, 2000). The last 100 responses in the $10 \mathrm{~Hz}$ trains were used to create scatter plots of the $n$th versus the $(n+$ 1)th amplitude. A plot of 13 individual experiments analyzed in this manner yielded a negative correlation between consecutive IPSC amplitudes, with a slope of $-0.055 \pm 0.028$ (Fig. $5 C)(n=$ $13 ; p<0.05)$. Linear regression of scatter plots from individual experiments showed a negative correlation in 10 of 13 experiments, with values ranging from -0.013 to -0.237 . These values of correlation are small, yet lie within the range of theoretical predictions (Matveev and Wang, 2000) and are comparable with the value reported in another experimental study on slow depression at inhibitory synapses (Kraushaar and Jonas, 2000). This result on the temporal correlation of consecutive releases shows that during steady-state synaptic depression, fluctuations in the amount of neurotransmitter release between consecutive stimuli are negatively correlated, consistent with vesicular depletion (Kraushaar and Jonas, 2000; Matveev and Wang, 2000), although additional presynaptic refractory processes may also contribute.

\section{Synaptic depression induced by prolonged stimulation of SJ1-deficient synapses}

Next, we studied the time course of slow synaptic depression in inhibitory pairs prepared from SJ1-ko mice (Fig. 6A,B). Repetitive stimulation at $10 \mathrm{~Hz}$ yielded a bi-exponential time course of synaptic depression, with decay constants of $0.18 \pm 0.01$ and $26.0 \pm 0.35 \mathrm{sec}(n=9)$. These values were not significantly different from those observed for wt synapses $(p>0.05)$. Thus, the overall course of synaptic depression was comparable for $\mathrm{wt}$ and SJ1-ko pairs, but the amplitude of the slow depression was greater in the SJ1-deficient synapses, starting with the stimulus number 77 (Fig. 6B) $(p<0.05)$. This increased sensitivity to repetitive stimulation led to a greater steady-state value of synaptic depression, equaling $18.2 \pm 0.2 \%$ for $10 \mathrm{~Hz}(n=9 ; p<$ $0.01)$ and $6.6 \pm 0.2 \%$ for $20 \mathrm{~Hz}(n=4 ; p<0.005)$. At $2 \mathrm{~Hz}$, the

$\leftarrow$

of $10 \mathrm{~Hz}$ trains (last 100 action potentials) in $\left[\mathrm{Ca}^{2+}\right] /\left[\mathrm{Mg}^{2+}\right]=2 \mathrm{~mm} / 2$ mM. Peak amplitudes $A_{\mathrm{n}+1}$ were plotted against the amplitudes $A_{\mathrm{n}}$ of the directly preceding IPSCs, both normalized to the mean amplitude of the dataset ( $n=13$ cell pairs, 1285 data points, 15 points outside of range plotted). Insets show plots of $A_{\mathrm{n}+1}$ versus $A_{\mathrm{n}}$ from two individual cells. Thick line represents the results of a linear regression with a slope $s=$ $-0.055(p<0.05)$. 
Figure 6. The lack of SJ1 results in a leftward shift of the relation between steady-state depression and stimulation frequency. $A$, Delivery of a $10 \mathrm{~Hz}, 1000 \times$ stimulus yielded increased steady-state depression in the SJ1-ko pair $(\bigcirc)$ compared with the wt pair $(\bigcirc)$. The two experiments were performed on the same day on cultures derived from the same litter. IPSC amplitudes were normalized to preceding baseline values obtained with $0.2 \mathrm{~Hz}$ stimulation. Top and bottom abscissa are as in Figure 4. $B$, Average time course of depression of SJ1-ko versus wt synapses during maintained $10 \mathrm{~Hz}$ stimulation ( $n=16$ for wt; $n=9$ for SJ1-ko). Plotted are normalized IPSC amplitudes derived from the average of five consecutive responses in the train (average starting with the second response in the train). Data are statistically different $(p<0.05)$ starting with the averaged responses to stimuli 77-82. Inset plots $p$ values from Student's $t$ test as a function of action potential number (title of abscissa not indicated in inset). $C$, Steady-state amplitude of inhibitory wt and SJ1-ko synapses as a function of stimulation frequency. For wt synapses (-), the frequency leading to a $50 \%$ depression was $f_{\text {crit }}=6.0 \pm 0.5 \mathrm{~Hz}$. For SJ1-ko synapses, $f_{\text {crit }}=$ $3.3 \pm 0.9 \mathrm{~Hz}$. Steady-state amplitudes for $2 \mathrm{~Hz}$ were measured at responses $501-550$, for $10 \mathrm{~Hz}$ at responses 651-700, and for $20 \mathrm{~Hz}$ at responses 951-1000. D, Recovery from synaptic depression induced at $10 \mathrm{~Hz}$, assessed with single stimuli delivered at $1 \mathrm{~Hz}$, starting $1 \mathrm{sec}$

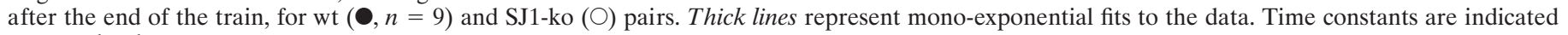
next to the data sets.
A
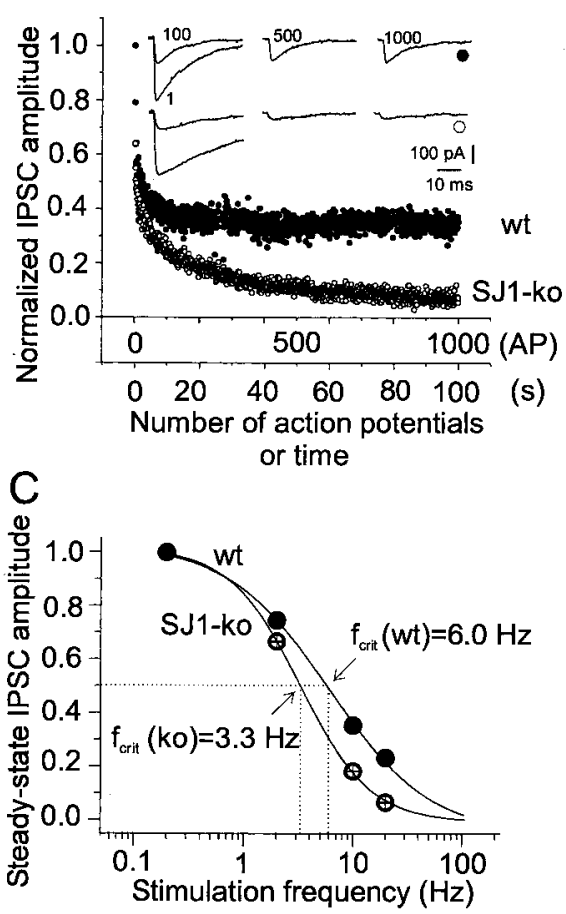

B
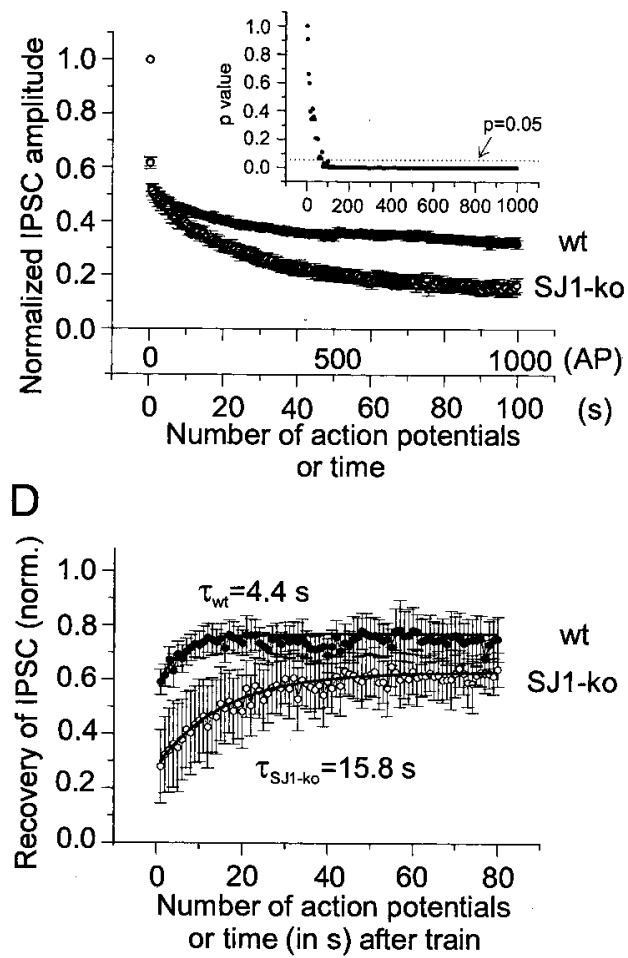

steady-state depression was $66.6 \pm 0.2 \%(n=6 ; p<0.001)$. To compare the sensitivity of wt and SJ1-ko synapses to repetitive stimulation, the steady-state synaptic depression was plotted against stimulation frequency. This yielded a sigmoidal relationship with a critical frequency ( $f_{\text {crit }}$, frequency for halfmaximal depression) of $6.0 \pm 0.5 \mathrm{~Hz}$ for the wt inhibitory pairs (Fig. 6C), in close agreement with the value reported for basket cells in the dentate gyrus or for fast-spiking neurons in neocortex $(\sim 5 \mathrm{~Hz})$ (Galarreta and Hestrin, 1998; Kraushaar and Jonas, 2000). This curve was shifted to the left for the SJ1-ko pairs, with a critical frequency being reached at $3.3 \pm 0.9 \mathrm{~Hz}$ (Fig. 6C). The leftward placement of the steady-state depression in these animals indicates that the lack of SJ1 leads to an increased sensitivity of inhibitory synapses to ongoing stimulation.

Recovery from depression was studied by applying 80 pulses at $1 \mathrm{~Hz}$, starting $1 \mathrm{sec}$ after the end of the $10 \mathrm{~Hz}$ train (Fig. 6D). Recordings from SJ1-ko pairs showed a significantly increased depression at the onset of the recovery $(28.1 \pm 13.4 \%, n=4$, vs $59.1 \pm 4.7 \%, n=9 ; p<0.05)$, and the time course was slowed down significantly (Fig. $6 D$ ). The time constant of recovery from SJ1-ko pairs was $15.8 \pm 1.0 \mathrm{sec}(n=9)$ compared with $4.4 \pm 0.7$ sec for wt pairs (Fig. $4 D$ ). Thus, recovery from slow depression in SJ1-ko pairs was $\sim 3$.6-fold slower compared with wt synapses.

Prolonged release of GABA may lead to high postsynaptic receptor occupancy and promote receptor desensitization, thereby inducing a deceleration of the falling phase of the IPSC (Jones and Westbrook, 1995). To address this issue, we determined the time course of decay of the IPSC by mono-exponential fitting of the responses in the $10 \mathrm{~Hz}$ train. This showed that the response decay was accelerated by $15.6 \pm 4.0 \%(n=16 ; p<0.05)$ at the end (last 10 responses) compared with the beginning (first
10 responses) of the train. We found a similar extent of IPSC acceleration in SJ1-ko animals $(15.1 \pm 6.2 \% ; n=9 ; p>0.05)$. Thus, although receptor desensitization may have occurred in this protocol, the relatively small change in IPSC decay time suggests that it is not substantial. Additional mechanisms shaping postsynaptic responses and possibly contributing to synaptic depression cannot be excluded. The extent of these effects is comparable, however, between wt and SJ1-ko animals and appears not to be related to the difference in steady-state depression between wt and SJ1-ko animals.

\section{DISCUSSION}

We have characterized inhibitory synaptic transmission between pairs of neurons in primary cultures of cortical neurons. At these synapses, we determined two temporally separate forms of depression that showed characteristics of predominantly presynaptically mediated processes. The slow, but not the fast, component of depression was increased in the SJ1-ko pairs, and basic properties of synaptic transmission remained unchanged. Because a major function of SJ1-sensitive phosphoinositide pools seems to be the regulation of clathrin coat and actin dynamics at endocytic zones of the presynaptic terminals (Cremona et al., 1999; Gad et al., 2000; Harris et al., 2000), these findings point to a critical role of synaptic vesicle recycling in the long-term stability of inhibitory neurotransmission.

The present work confirms and extends earlier evidence for a role of SJ1 in synaptic transmission (Cremona et al., 1999). Thus, in these previous studies, we found that synaptic depression of Schaffer collateral responses in CA1 hippocampal neurons was increased in slices derived from SJ1-ko animals. However, this result could not be interpreted unambiguously. First, the slices 
were derived from animals at a time that only slightly predates the invariable death at approximately postnatal day 15 . The major growth defects resulting from failure to thrive may have caused nonspecific effects on the function of synapses. Second, shortterm synaptic plasticity at Schaffer collateral terminals displays a complex time course with both facilitatory and depressant phases, which in these experiments were not fully characterized with respect to the involvement of presynaptic mechanisms. Therefore, the question remained whether the morphological and biochemical evidence for a role of SJ1 in vesicular recycling could be directly related to the observed impairment of synaptic transmission. The inhibitory connection, with its clearly separable dual phases of synaptic depression, appeared to represent an ideal target for addressing this question.

Prolonged periods of stimulation were applied with the goal of reaching a high level of vesicular depletion in presynaptic terminals. This approach is complicated by the fact that many, temporally overlapping presynaptic and postsynaptic factors involved in neurotransmission are sensitive to repetitive activity. Conditions of stimulation were chosen to circumvent or at least minimize use-dependent mechanisms of synaptic depression not directly involving the release process. Thus, stimulation frequencies were comparatively moderate such that the waveform of the presynaptic action potentials at the soma was largely preserved (although the waveform at presynaptic terminals could not be monitored), and significant inactivation or facilitation of presynaptic $\mathrm{Ca}^{2+}$ currents was unlikely to occur (von Gersdorff and Matthews, 1997; Borst and Sakmann, 1998; Cuttle et al., 1998; Forsythe et al., 1998; Wang and Kaczmarek, 1998). Furthermore, IPSC waveforms did not overlap, and baseline holding current was restored after every stimulus; therefore, excessive GABA accumulation leading to usedependent changes in receptor properties was minimized, an interpretation supported by the comparatively minor changes in IPSC waveform at the end of the train. Furthermore, with the stimulation protocols used, presynaptic $\mathrm{GABA}_{\mathrm{B}}$ receptor activation was previously reported to contribute only a small portion to slow depression in fast-spiking inhibitory neurons in both acute and cultured hippocampal preparations (Jensen et al., 1999; Kraushaar and Jonas, 2000). Finally, we studied the extent of synaptic depression at potentials hyperpolarized to the reversal potential, which should promote homeostasis of $\left[\mathrm{Cl}^{-}\right]_{\mathrm{i}}$ and minimize activity-dependent changes in the driving force for $\mathrm{Cl}^{-}$(Thompson and Gähwiler, 1989). However, even if significant changes in $\left[\mathrm{Cl}^{-}\right]_{\mathrm{i}}$ were to occur with our protocol, it is unlikely that these would be different between the SJ1-ko and wt mice. Taken together, the comparatively moderate stimulation protocols used in our experiments are likely to leave relatively unaffected crucial steps in synaptic transmission and favor the possibility that the biphasic synaptic depression may be mechanistically associated with the vesicular release and recycling machinery.

Paired-pulse depression at inhibitory cultured synapses has been attributed to predominantly presynaptic mechanisms causing a decrease in release probability with a recovery interval of typically a few seconds and a minimal contribution of postsynaptic mechanisms (Wilcox and Dichter, 1994; Jensen et al., 1999; Kraushaar and Jonas, 2000). The amplitude of PPD and its time course of recovery in our work agree with reports from both cultured (Wilcox and Dichter, 1994; Jensen et al., 1999) and acute preparations involving fast-spiking presynaptic cells (Jiang et al., 2000; Kraushaar and Jonas, 2000), indi- cating that short-term plasticity in the cultured cell pairs studied was preserved and may be generated by similar mechanisms. Thus, we found that PPD was largely independent of extracellular divalent cation concentration ratios, arguing against a presynaptic depletion process, and was present at time intervals outlasting $\mathrm{GABA}_{\mathrm{A}}$ receptor desensitization (Jones and Westbrook, 1995). Finally, previous studies have shown that PPD at fast-spiking hippocampal inhibitory terminals only marginally depends on activation of $\mathrm{GABA}_{\mathrm{B}}$ receptors (Jensen et al., 1999; Kraushaar and Jonas, 2000). Pairedpulse depression may be caused by some desensitization or inactivation process intrinsic to the synaptic release step or to upstream events. Moreover, rapid depression induced by more than two stimuli between $2-20 \mathrm{~Hz}$ may be caused, at least in part, by an accumulation of the events underlying PPD, as suggested by the release independence of rapid depression, its recovery within time scales comparable to PPD, and its description as a summation of the effects triggered by individual action potentials. The preservation of normal PPD and rapid depression in SJ1-deficient pairs provides an additional confirmation of the relatively selective nature of the deficit induced by knock-out of SJ1, namely an increased depression and slowed recovery associated only with prolonged vesicular release.

In the slow second phase of synaptic depression at inhibitory synapses, amplitudes of IPSCs are greatly stabilized. Then, the rate of vesicular release per stimulus must balance the number of vesicles recycled into the releasable vesicle pools, suggesting that at this point a mechanism contributing to the refill of these may become rate limiting. Interestingly, the releasable pool (likely containing the RRP and a presumed reserve pool) in hippocampal basket cells (which show properties similar to those described in this study) has been recently estimated to contain $\sim 50$ vesicles that are released with a probability of $\sim 0.4-0.6$ (Kraushaar and Jonas, 2000). Therefore, it may take at least 100 action potentials to significantly deplete the releasable pool, consistent with slow depression developing within hundreds of stimuli in our preparation. Moreover, we found that enhancing release probability by tripling the ratio of extracellular $\left[\mathrm{Ca}^{2+}\right] /\left[\mathrm{Mg}^{2+}\right]$ led to an enhancement of the slow depression after $\sim 100$ action potentials and that during steadystate depression subsequent release events were, on average, negatively correlated (Jensen et al., 1999; Kraushaar and Jonas, 2000). Together with the selective deficit of SJ1-deficient synapses in this slow form of depression, these data provide molecular support for the need of vesicle delivery to the pool available for release after a train of $\sim 100$ action potentials, for example via recycling of endocytosed vesicles or translocating vesicles between pools. It is possible that SJ1-dependent involvement in size regulation of the RRP or in other recycling and transport pathways (Pyle et al., 2000) could also play a role. The present data therefore further support association of slow synaptic depression with the morphological picture of vesicle depletion (Liley and North, 1953; Elmqvist and Quastel, 1965; Jensen et al., 1999; Weis et al., 1999; Kraushaar and Jonas, 2000).

Given the multiple functions of phosphoinositides that serve as substrates of SJ1 (McPherson et al., 1996; Woscholski et al., 1997; Cremona et al., 1999; Guo et al., 1999), the possibility needs to be considered that the absence of this protein may cause multiple changes in presynaptic processes in addition to its effects on vesicle traffic. For example, the increased presence of 
phosphatidylinositol-4,5-bisphosphate in SJ1-ko animals (Cremona et al., 1999) may cause an increase in cellular levels of inositol trisphosphate and, in turn, in presynaptic ambient $\left[\mathrm{Ca}^{2+}\right]$. The preservation of basic properties of synaptic transmission, including the size of monosynaptic responses and the properties of PPD, argues against a physiological impact of such potential effects on $\mathrm{Ca}^{2+}$ signaling pathways. Other effects, however, induced by modification of the SJ1-sensitive phosphoinositide pools should be considered. Although our results clearly implicate SJ1 in the maintenance of inhibitory synaptic transmission, it is premature to link a decreased stability of transmission only to a defect in endocytosis.

In recent years, advances in optical and capacitive measurement techniques have provided a more direct view into links between synaptic depression, depletion of vesicle pools, and recycling rates (Pieribone et al., 1995; Ryan, 1996; von Gersdorff and Matthews, 1997; Delgado et al., 2000; Pyle et al., 2000; Sankaranarayanan and Ryan, 2001). It appears that to ensure the stability of synaptic transmission at higher frequencies, a substantial amount of vesicle trafficking between pools takes place. Our results on the role of $\mathrm{SJ} 1$ suggest that, in the future, the analysis of short-term plasticity of neurons deficient in proteins controlling vesicle reformation may be a diagnostic tool to help elucidate the role of vesicle recycling in synaptic transmission in the mammalian CNS.

\section{REFERENCES}

Augustine GJ, Burns ME, DeBello WM, Hilfiker S, Morgan JR, Schweizer FE, Tokumaru H, Umayahara K (1999) Proteins involved in synaptic vesicle trafficking. J Physiol (Lond) 520:33-41.

Banker G, Goslin K (1991) Culturing nerve cells. Cambridge, MA: MIT.

Borst JGG, Sakmann B (1998) Facilitation of presynaptic calcium currents in the rat brainstem. J Physiol (Lond) 513:149-155.

Brodin L, Löw P, Gad H, Gustafsson J, Pieribone VA, Shupliakov O (1997) Sustained neurotransmitter release: new molecular clues. Eur J Neurosci 9:2503-2511.

Brodin L, Löw P, Shupliakov O (2000) Sequential steps in clathrinmediated synaptic vesicle endocytosis. Curr Opin Neurobiol 10:312-320.

Ceccarelli B, Hurlbut WP (1980) Vesicle hypothesis of the release of quanta of acetylcholine. Physiol Rev 60:396-441.

Cremona O, De Camilli P (2001) Phosphoinositides in membrane traffic at the synapse. J Cell Sci 114:1041-1052.

Cremona O, Di Paolo G, Wenk MR, Lüthi A, Kim WT, Takei K, Daniell L, Nemoto Y, Shears SB, Flavell RA, McCormick DA, De Camilli P (1999) Essential role of phosphoinositide metabolism in synaptic vesicle recycling. Cell 99:179-188.

Cuttle MF, Tsujimoto T, Forsythe ID, Takahashi T (1998) Facilitation of the presynaptic calcium current at an auditory synapse in rat brainstem. J Physiol (Lond) 512:723-729.

Debanne D, Guérineau NC, Gähwiler BH, Thompson SM (1996) Paired-pulse facilitation and depression at unitary synapses in rat hippocampus: quantal fluctuation affects subsequent release. J Physiol (Lond) 491:163-176.

De Camilli P, Emr SD, McPherson PS, Novick P (1996) Phosphoinositides as regulators in membrane traffic. Science 271:1533-1539.

De Camilli P, Slepnev VI, Shupliakov O, Brodin L (2000) Synaptic vesicle endocytosis. In: Synapses (Cowan M, Südhof T, Stevens C, eds), pp 217-274. Baltimore: Johns Hopkins UP.

Delgado R, Maureira C, Oliva C, Kidokoro Y, Labarca P (2000) Size of vesicle pools, rates of mobilization, and recycling at neuromuscular synapses of a Drosophila mutant, shibire. Neuron 28:941-953.

Dittman JS, Regehr WG (1998) Calcium dependence and recovery kinetics of presynaptic depression at the climbing fiber to Purkinje cell synapse. J Neurosci 18:6147-6162.

Elmqvist D, Quastel DM (1965) A quantitative study of endplate potentials in isolated human muscle. J Physiol (Lond) 178:505-529.

Forsythe ID, Tsujimoto T, Barnes-Davies M, Cuttle MF, Takahashi T (1998) Inactivation of presynaptic calcium current contributes to synaptic depression at a fast central synapse. Neuron 20:797-807.

Gad H, Ringstad N, Löw P, Kjaerulff O, Gustafsson J, Wenk M, Di Paolo G, Nemoto Y, Crun J, Ellisman MH, De Camilli P, Shupliakov O,
Brodin L (2000) Fission and uncoating of synaptic clathrin-coated vesicles are perturbed by disruption of interactions with the $\mathrm{SH} 3 \mathrm{do}-$ main of endophilin. Neuron 27:301-312.

Galarreta M, Hestrin S (1998) Frequency-dependent synaptic depression and the balance of excitation and inhibition in the neocortex. Nat Neurosci 1:587-594.

Guo S, Stolz LE, Lemrow SM, York JD (1999) SAC1-like domains of yeast SAC1, INP52, and INP53 and of human synaptojanin encode polyphosphoinositide phosphatases. J Biol Chem 274:12990-12995.

Gupta A, Wang Y, Markram H (2000) Organizing principles for a diversity of GABAergic interneurons and synapses in the neocortex. Science 287:273-278.

Haffner C, Takei K, Chen H, Ringstad N, Hudson A, Butler MH, Salcini AE, Di Fiore PP, De Camilli P (1997) Synaptojanin 1: localization on coated endocytic intermediates in nerve terminals and interaction of its $170 \mathrm{kDa}$ isoform with Eps15. FEBS Lett 419:175-180.

Harris TW, Hartwieg E, Horvitz HR, Jorgensen EM (2000) Mutations in synaptojanin disrupt synaptic vesicle recycling. J Cell Biol 150:589-599.

Jensen K, Lambert JDC, Jensen MS (1999) Activity-dependent depression of GABAergic IPSCs in cultured hippocampal neurons. J Neurophysiol 82:42-49.

Jiang L, Sun S, Nedergaard M, Kang J (2000) Paired-pulse modulation at individual GABAergic synapses in rat hippocampus. J Physiol (Lond) 523:425-439.

Jones MV, Westbrook GL (1995) Desensitized states prolong GABA channel responses to brief agonist pulses. Neuron 15:181-191.

Kraushaar U, Jonas P (2000) Efficacy and stability of quantal GABA release at a hippocampal interneuron-principal neuron synapse. J Neurosci 20:5594-5607.

Kudo M, Saito S, Sakagami H, Suzaki H, Kondo H (1999) Localization of mRNAs for synaptojanin isoforms in the brain of developing and mature rats. Brain Res Mol Brain Res 64:179-185.

Lee SH, Rosenmund C, Schwaller B, Neher E (2000) Differences in $\mathrm{Ca}^{2+}$ buffering properties between excitatory and inhibitory hippocampal neurons from the rat. J Physiol (Lond) 525:405-418.

Liley AW, North KAK (1953) An electrical investigation of effects of repetitive stimulation on mammalian neuromuscular junction. J Neurophysiol 16:509-527.

Lüthi A, Di Paolo G, Daniell L, Cremona O, De Camilli P, McCormick DA (2000) Synaptojanin, a polyphosphoinositide phosphatase, is important in maintaining cortical inhibitory synaptic transmission. Soc Neurosci Abstr 26:128.9.

Matveev V, Wang XJ (2000) Implications of all-or-none synaptic transmission and short-term depression beyond vesicle depletion: a computational study. J Neurosci 20:1575-1588.

McPherson PS, Garcia EP, Slepnev VI, David C, Zhang X, Grabs D, Sossin WS, Bauerfeind R, Nemoto Y, De Camilli P (1996) A presynaptic inositol-5-phosphatase. Nature 379:353-357.

Neher E (1992) Correction for liquid junction potentials in patch clamp experiments. Methods Enzymol 207:123-131.

Neher E (1998) Vesicle pools and $\mathrm{Ca}^{2+}$ microdomains: new tools for understanding their roles in neurotransmitter release. Neuron 20:389-399.

Nitsch R, Soriano E, Frotscher M (1990) The parvalbumin-containing nonpyramidal neurons in the rat hippocampus. Anat Embryol 181:413-425

Owen DJ, Luzio JP (2000) Structural insights into clathrin-mediated endocytosis. Curr Opin Cell Biol 12:467-474.

Pieribone VA, Shupliakov O, Brodin L, Hilfiker-Rothenfluh S, Czernik AJ, Greengard P (1995) Distinct pools of synaptic vesicles in neurotransmitter release. Nature 375:493-497.

Pyle JL, Kavalali ET, Piedras-Rentería ES, Tsien RW (2000) Rapid reuse of readily releasable pool vesicles at hippocampal synapses. Neuron 28:221-231.

Ryan TA (1996) Endocytosis at nerve terminals: timing is everything. Neuron 17:1035-1037.

Ryan TA, Li L, Chin LS, Greengard P, Smith SJ (1996) Synaptic vesicle recycling in synapsin I knock-out mice. J Cell Biol 134:1219-1227.

Sankaranarayanan S, Ryan TA (2001) Calcium accelerates endocytosis of vSNAREs at hippocampal synapses. Nat Neurosci 4:129-136.

Slepnev VI, De Camilli P (2000) Accessory factors in clathrindependent synaptic vesicle endocytosis. Nat Rev Neurosci 1:161-172.

Thompson SM, Gähwiler BH (1989) Activity-dependent disinhibition. I. Repetitive stimulation reduces IPSP driving force and conductance in the hippocampus in vitro. J Neurophysiol 61:501-511.

Thomson AM (2000) Molecular frequency filters at central synapses. Prog Neurobiol 62:159-196.

Thomson AM, Deuchars J (1997) Synaptic interactions in neocortical local circuits: dual intracellular recordings in vitro. Cereb Cortex 7:510-522.

Tóth K, McBain CJ (2000) Target-specific expression of pre- and postsynaptic mechanisms. J Physiol (Lond) 525:41-51.

Varela JA, Song S, Turrigiano GG, Nelson SB (1999) Differential de- 
pression at excitatory and inhibitory synapses in visual cortex. J Neurosci 19:4293-4304.

von Gersdorff H (2001) Synaptic ribbons: versatile signal transducers. Neuron 29:7-10.

von Gersdorff H, Matthews G (1997) Depletion and replenishment of vesicle pools at a ribbon-type synaptic terminal. J Neurosci 17:1919-1927.

Wang LY, Kaczmarek LK (1998) High-frequency firing helps replenish the readily releasable pool of synaptic vesicles. Nature 394:384-388.

Weis S, Schneggenburger R, Neher E (1999) Properties of a model of $\mathrm{Ca}^{++}$-dependent vesicle pool dynamics and short term synaptic depression. Biophys J 77:2418-2429.

Wilcox KS, Dichter MA (1994) Paired-pulse depression in cultured hip- pocampal neurons is due to a presynaptic mechanism independent of $\mathrm{GABA}_{\mathrm{B}}$ autoreceptor activation. J Neurosci 14:1775-1788.

Woscholski R, Finan PM, Radley E, Totty NF, Sterling AE, Hsuan JJ, Waterfield MD, Parker PJ (1997) Synaptojanin is the major constitutively active phosphatidylinositol-3,4,5-trisphosphate 5-phosphatase in rodent brain. J Biol Chem 272:9625-9628.

Wu LG, Betz WJ (1998) Kinetics of synaptic depression and vesicle recycling after tetanic stimulation of frog motor nerve terminals. Biophys J 74:3003-3009.

Zucker RS (1989) Short-term synaptic plasticity. Annu Rev Neurosci 12:13-31.

Zucker RS (1996) Exocytosis: a molecular and physiological perspective. Neuron 17:1049-1055. 